www.jmscr.igmpublication.org

Index Copernicus Value: 79.54

ISSN (e)-2347-176x ISSN (p) 2455-0450

crossref DOI: https://dx.doi.org/10.18535/jmscr/v7i3.234

\title{
Acute Reversible Hand Ischemia after Clindamycin injection
}

\author{
Authors \\ Harharpreet Kaur ${ }^{1 *}$, Santosh Minhas ${ }^{2}$, S.S. Minhas ${ }^{3}$, Kiran Kumar Singal ${ }^{4}$, \\ Sukhraj Pal Singh ${ }^{5}$ \\ ${ }^{1}$ Professor, Department of Medicine, MM Medical College, Kumarhatti,Solan \\ ${ }^{2}$ Professor, Department of Gynecology, MM Medical College, KumarhattiSolan \\ ${ }^{3}$ Professor, Department of Surgery, MM Medical College, Kumarhatti, Solan \\ ${ }^{4}$ Professor, Department of Medicine, MM Medical College, Kumarhatti, Solan \\ ${ }^{5}$ Senior Resident, Department of Medicine, MM Medical College, Kumarhatti, Solan \\ *Corresponding Author \\ Dr Harharpreet Kaur
}

Professor Medicine, MM Medical College, Kumarhatti, Distt. Solan, Himachal Pradesh, India Ph 9872777800, Email: dr.harharpreet@gmail.com

\begin{abstract}
Intravenous (IV) therapy is associated with a number of potential complications including ecchymosis, extravasation, hematoma, phlebitis, skin necrosis and air embolism. We report a case in which an intravenous injection of clindamycin dramatically produced deep cyanosis, ischemia and swelling of the injected hand which improved within 2-3 days. The underlying mechanism was possibly a vasospasm induced by the irritant action of the drug.

Keywords: Clindamycin; Injection; Cyanosis; Swelling; Hand;Vasospasm.
\end{abstract}

\section{Introduction}

Intravenous (IV) therapy is associated with complications like phlebitis, hematoma, ecchymosis, and extravasation. Extravasation is the inadvertent leakage of the drug from the blood vessel into the tissue spaces. Most drugs produce a self limiting inflammatory reaction. However there are certain drugs termed as vesicant drugs which may cause serious tissue injury by direct toxicity resulting in blisters and necrosis. The tissue damage that follows extravasation is related to the physico-chemical nature of these drugs including osmolarity, $\mathrm{pH}$, volume and concentration of the drug. Some examples of such vesicant drugs are vancomycin, amphotericin, phenytoin, and phenergan. Vaso constrictive drugs like dopamine, dobutamine and epinephrine can cause ischemic injury. Concentrated electrolyte and hyperosmolar solutions, cytotoxic agentsand radiographic contrast solutions are also known to produce local tissue damage. ${ }^{1}$ However ischemia induced by the irritant drugs is a less well recognized complication.

\section{Case Report}

Our patient was a 40 year old woman who had undergone hysterectomyand was postoperatively given clindamycin injection through an IV canula 


\section{JMSCR Vol||07||Issue||03||Page 1397-1400||March}

which was inserted on the dorsal aspect of the hand. She experienced severe pain as the drug was administered and shortly after the injection the fingers and palm began to develop a swelling and bluish discoloration. Within a few hours the whole hand was cold, cyanosed, painful and oedematous. (Fig 1and Fig 2). The pulse was feeble. No blisters or necrosis were observed. The patient was restless. Heart rate was $110 / \mathrm{min}$ and respiratory rate $30 / \mathrm{min}$. She was given supportive treatment including Injection Hydrocortisone, diuretic and intravenous heparin keeping all possibilities in mind pending the investigations. The cyanosis started improving after another 4-5 hours and the swelling subsided with 2-3 days.(Fig 3)

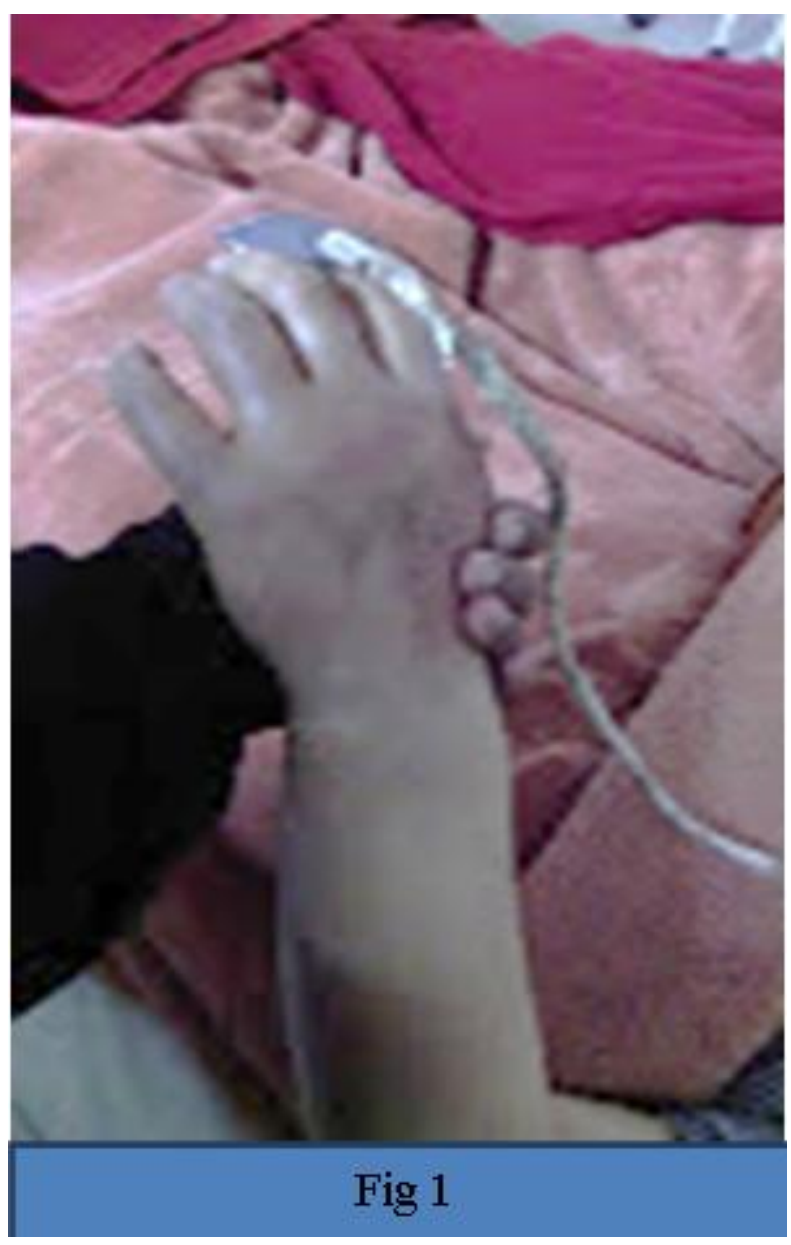

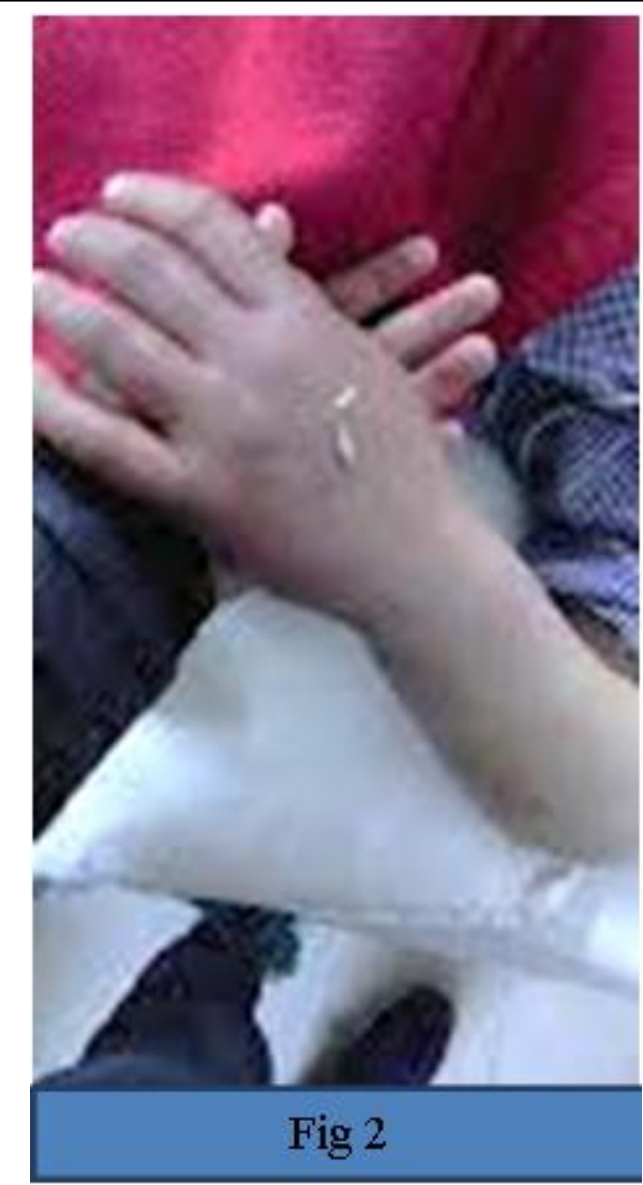

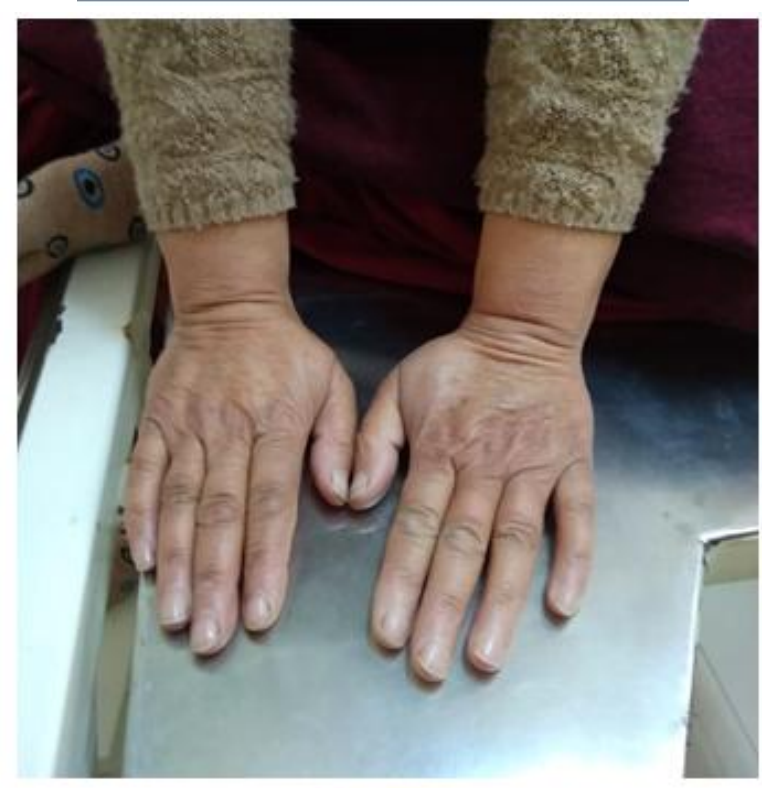

Fig 3

\section{Discussion}

Clindamycin has been mentioned in the list of agents commonly involved in extravasation injuries. $^{2}$ On review of literature we found a single case of clindamycin injection in which a 14 year old boy who was given clindamycin injection developed painful swelling of the forearm and later developed a wrist drop due to necrosis of 
forearm extensor muscles. ${ }^{3}$ However in our patient the swelling subsided within a few days. There was no superficial skin damage. The cold, blue and cyanosed hand was indicative of acute limb ischemia. The mechanism operating in its pathogenesis had to be occlusion in the vascular compartment. Since the ischemia was reversible a venous spasm is one plausible explanation. Venous spasm which has been described as a complication of intravenous drug therapy is an abrupt involuntary constriction of a vein or an artery causing a temporary cessation of the blood flow. It is known to cause severe pain during injection which was present in our patient. Venospasm is induced by drug-related irritation and trauma to the vein, directly or by the extravasated drug. It has been suggested the venospasmmay provoke further neurogenic discharges causing an increase in both venous and arterial tone in the adjoining vascular bed which aggravates ischemia ${ }^{4}$. Thus ischemia is likely to be perpetuated by the reflex vasospasm in the neighbouring vessels especially when there is associated irritation by the extravasation of the drug.

Drainage of the deoxygenated venous blood is impaired by the venous occlusion which in turn leads to backpressure and fluid leakage from the capillaries into the tissue spaces causing oedema of the hand. According to Walker et al the increased capillary permeability may be aggravated by the biotoxins that accumulate at the site of the occlusion because of acute limb ischemia. ${ }^{5}$ Research by Ellertson et al also supports the view that the venospasm and associated thrombosis lead to outflow obstruction, followed by cyanosis, transudation, edema, and finally arterial stasis which lead to ischemic necrosis $^{6}$

In a case reported by Webster et $\mathrm{al}^{7}$ similar dramatic cyanosis and swelling of the hand as in our case was observed after an injections given in the veins on the dorsum of the hand. The reporter suggested the possibility ofa venous spasm, followed by venous thrombosis as the cause of the vascular changes. Alternatively, leakage of the drug from the vein into the interstitial tissues, may have produced the local reaction.

The possibility of an accidental arterial injection also cannot be ruled out. Arterial spasm directly mediated by the drug or caused by the local release of norepinephrine after an intra-arterial (IA) injection may cause severe acute ischemia and gangrene of the extremity. ${ }^{8} \mathrm{~A}$ number of variations of the superficial arch and the deep palmar arch have been described which may not be very deep. ${ }^{9}$ It has been suggested that in a normal hand branches of the dorsal carpal arterial arch, and perforating branches of the deeppalmar arterial arch run relatively superficially and may be damaged or cannulated accidentaly. ${ }^{10}$

\section{Conclusion}

Thus it is recommended that clindamycin injection being an irritant drug should be administered in form of an infusion after proper dilution. In the eventuality of the development of a blue cyanosed extremity vasodilators may be considered. The possibility of associated thrombosis post trauma to the vein cannot be ruled out so early heparin administration is suggested. Hand should be elevated to reduce swelling. Steroids and diuretics may have a role in reducing inflammation and swelling and the accompanying systemic reaction. In the case reported by Webster et al stellate ganglion block was given. Clindamycin is a very commonly used antibiotic. Awareness is needed regarding its safe use and management of an unusual complication such as this.

\section{References}

1. Lateef F: Extravasation: there could be more than meets the eye! J Trauma Crit Care. 2017; 1:1

2. Goutos, Cogswell LK, Giele H. Extravasation injuries: a review. J Hand. SurgEur Vol. 2014 Oct;39(8):808-18. 
3. Dahal P, Shrestha JM: Extravasation Injury of the Upper Limb by Intravenous Clindamycin Postgraduate Medical Journal of NAMS 2011Volume 11,Number 2

4. Alexander, R. S.: The peripheral venous system. in Hamilton. W. F. and Dow. P.: Hand- book of physiology, Section 2, Circulation, 31, Washington, D. C., 1963, vol. 2, p. 1086, American Physiological Society

5. Walker T. Gregory (. "Acute Limb ischemia". Techniques in Vascular and Interventional Radiology. (2009)12 (2): 117-129.

6. Ellertson DG, Lazarus HM, Auerbach R. Patterns of acute vascular injury after intra-arterial barbiturate injection. Am J Surg. 1973;126:813-817

7. Webster J L. Oedema and cyanosis of the Hand following injections into the vein on the Dorsum of the hand A Case Report Brit. J. Anaesth. (1964), 36, 50

8. Cohen S. Accidental intra-arterial injections of drugs. Lancet 1948; 2: 36171

9. Kaplan EB, Spinner M. Kaplan's Functional and Surgical Anatomy ofthe Hand. 3rd ed. Philadelphia, Pa: Lippincott; 1984.

10. Baillie, T. W. Accidental intra-arterial injection of thiopentone on the back of the hand. (1958). Brit. J.Anaesth., 30, 373. 